\title{
Teaching and Research Opportunities in Technology Entrepreneurship
}

Simon Mosey

Haydn Green Institute for Innovation and Entrepreneurship, University of Nottingham, UK.

\section{Introduction}

Technology entrepreneurship as a discipline of study has come of age. The international research community is no longer debating what technology entrepreneurship means or spending time justifying its importance. We are rather engaged in building theory to encourage and enhance technology entrepreneurship in those organisations and institutions that wish to do so. In this paper, we define technology entrepreneurship as the interface between the more established academic fields of entrepreneurship and technology based innovation (Beckman et al, 2012). We argue that novel insights are more likely to be found at such interfaces as we highlight opportunities for new teaching and research approaches.

\section{Teaching Opportunities}

Siegel and Wright (2015) suggest that researchers should refocus their efforts away from the well studied area of the commercialisation of research to the relatively unexplored area of technology entrepreneurship education. Such education has shown a profound shift in both scale and scope of provision. Clarysse et al (2009) looked at international best practice and found a change in both the supply and demand side. In terms of supply the historical dominance of universities, where business schools offered MBAs to ambitious engineers and scientists was observed to be super-ceded by alternative providers such as technology start up accelerators, often managed by entrepreneurs or venture funds. Considering demand, a comparable shift was seen away from the need for research and general management skills towards scientists seeking start up and venture growth capabilities. Clarysse et al (2009) explored how universities were coping with this rapid and global change in pedagogical approach and skills requirements. They concluded that universities could make a valuable contribution but were constrained by a significant shortfall in terms of faculty experience of teaching in such an inherently cross disciplinary and experiential manner.

An example of the benefits of universities engaging in this new space can be seen through the Universitas 21 Global Ingenuity Challenge (www.universitas21.com). Here globally dispersed students were invited to work in virtual cross disciplinary teams to address grand societal challenges. In the 2016 competition the challenge posed was that of providing sustainable housing and student teams from 16 universities explored how technology breakthroughs could be deployed to create high growth new ventures. The competition used a bespoke software platform to help the students to interact virtually with expert mentors and the final solutions were posted online as video pitches which were then judged by an international panel. Despite the fact the student teams only had two weeks to work on the challenge, the resulting pitches were remarkable in terms of their integration of innovation and pragmatism. Two winners were chosen, the first from South Korea focussed upon the problem of single person households and developed a solution using the internet of things to reconnect individuals to society. The second, from Michigan addressed the challenge of urban decay, and offered a micro credit scheme to encourage local entrepreneurs to revitalise areas of low employment. In these examples you can observe 
the influence of students from the different disciplines of architecture, computer science, sociology and economics working together across international boundaries to address specific regional issues. Such a blended learning approach promises an elegant solution to the lack of locally available and experienced faculty. Nevertheless, there is a pressing need for the efficacy and impact of this and other contemporary interventions such as technology accelerator programmes to be more fully explored and disseminated.

\section{Research Opportunities}

There is a long tradition of research considering the impact of education upon technology entrepreneurship. Marvel and Lumpkin (2007) showed how human capital gained through university education has a generally positive influence upon technology venture performance, when other factors are controlled for. The complexity of this relationship was examined in more detail by Eesley and Roberts (2012) who found that the relative importance of talent versus experience was context dependent, with experience dominating when the current market/ technology is familiar and vice versa. This work could be fruitfully developed to explore the influence of talent versus experience upon the performance of individuals and firms taking part in hackathons, accelerators and crowd funding platforms, and help to unpick the influence of those experiences upon the human capital of the individuals concerned (Mosey et al 2016).

We suggest that the University is an ideal setting to conduct such research, especially if individual level studies are extended to consider the influence of different levels of analysis. For instance, recent work considering which factors enhance the entrepreneurial performance of the intermediary level of the research group is showing great promise. Matsumoto et al (2010) extended the individual level consideration of 'star scientists' into the research group and found that members of groups led by a star scientist gain benefits in research performance in addition to increased levels of innovation. Considering higher level influences upon research groups appears equally fruitful. Rasmussen et al's (2013) work showed that if a head of department took even a slightly benign approach towards entrepreneurship (as opposed to being actively supportive) this had a disproportionately negative influence upon the likely performance of spin offs from research groups within that department. This shows that managing the conflicting logics between the pursuit of science and entrepreneurship to be a very delicate balance and highlights the need for more studies to tease out other contextual influences (Perkmann and Salter, 2012).

In sum, technology entrepreneurship as a field has evolved to reveal many promising empirical opportunities for study. These include student and alumni start up competitions, accelerators, collaborative networks and crowdsourcing. In addition to the novel pedagogical aspects of these models, they also provide new governance structures for researchers to consider such as social enterprises and public-private incubators. To capture and better explain these phenomena, researchers will need to be open to different theoretical approaches. We need to be cognisant of the limitations of our traditional economics and strategy based approaches and embrace different schema such as sensemaking, evolutionary theory, knowledge spill-overs and entrepreneurial ecosystems (Mosey et al, 2016).

Technology entrepreneurship has come of age so please come and join the birthday celebrations! 


\section{References}

Beckman, C. M., Eisenhardt, K., Kotha, S., Meyer, A., \& Rajagopalan, N. (2012). Technology entrepreneurship. Strategic Entrepreneurship Journal, 6(2), 89-93.

Clarysse, B.; Mosey, S.; Lambrecht, I.(2009)., New Trends in Technology Management Education: A View from Europe, Academy of Management Learning and Education, Vol.8(3) Sept 2009.

Eesley, C. E. \& Roberts, E. B. (2012), Are You Experienced or Are You Talented?: When Does Innate Talent versus Experience Explain Entrepreneurial Performance?. Strategic Entrepreneurship Journal, 6, 207-219.

Marvel, M. R., \& Lumpkin, G. T. (2007). Technology entrepreneurs' human capital and its effects on innovation radicalness. Entrepreneurship Theory and Practice, 31(6), 807-828.

Matsumoto, M., Yokota, S., Naito, K. and Itoh, J. (2010), Development of a model to estimate the economic impacts of R\&D output of public research institutes. R\&D Management, 40, 91-100.

Mosey, S.; Guerreo, M.; Greenman, A.(2016)., Technology entrepreneurship research opportunities: insights from across Europe, Journal of Technology Transfer. DOI 10.1007/s10961-015-9462-3.

Perkmann, M. and Salter, A. (2012). How to create productive partnerships with Universities. MIT Sloan Management Review. 53, 79-88.

Rasmussen, E., Mosey, S. \& Wright, M. (2013). The influence of university departments on the evolution of entrepreneurial competencies in spin-off ventures, Research Policy, Vol.43 (1), pp. 92106.

Siegel, D.S., \& Wright, M. (2015), Academic Entrepreneurship: Time for a Rethink? British Journal of Management. Vol. 26 (4): 582-595. 